\title{
Total Factor Productivity in the Building Construction Industry in Sri Lanka
}

\author{
Dimuth Navaratna and A K W Jayawardane
}

\begin{abstract}
This research study uses the Tornqvist Index method to estimate the Total Factor Productivity Growth (TFPG) of the Sri Lanka building construction industry from 1995 ñ 2001. The original objective of looking at the entire construction industry (building, water, roads, etc.) had to be abandoned due to limited availability of data and incompleteness of the available data. The results of the study indicate that TFPG has a positive trend from 1995 to 1997 and recorded the maximum TFPG in 1997. However, there is a drastic drop in TFPG (from +0.803 to $\tilde{n}$ 0.682) in the building construction in 1998 and 1999 due to very high labour and capital input compared to 1997. Since year 2000 TFPG in the building construction industry had been revolving around zero. Study also concludes that there has to be significant improvement in national data collection in order to have more reliable indicators of TFPG trends in the building industry and the overall construction industry.
\end{abstract}

Key Words: Total Factor Productivity (TFP), Total Factor Productivity Growth, Tornqvist Method Department of Census and Statistics (DC\&S), Building Construction Industry, Sri Lanka.

\section{Introduction}

Construction industry is an important industry in any country, especially in developing countries as any development must essentially follow a booming construction industry involving significant infrastructure development. To this end, Sri Lanka construction industry with over $50 \%$ share of Gross Fixed Capital Formation and around 7\% of Gross Domestic Product, has received mixed blessings from the government and policy makers [3]. Development of the construction industry is facilitated by the Institute for Construction. Training. and Development (ICTAD) and is responsible for registering contractors, providing training, introducing standard documents such as Conditions of Contract, specifications, facilitating research and consultancy to address industry issues and to assist in policy making. Other bodies such as the Institution of Engineers Sri Lanka, National Construction Contractors Association, Association of Consulting Engineers, recently established Chamber of Construction Industry, other professional bodies and educational institutions provide supportive roles for its development. Although the Sri Lankan contractors receive $10 \%$ preference over foreign contractors in bidding [5], the government has given insufficient attention to protect and develop Sri Lankan contractors. Thus, Sri Lanka construction industry does not seem to be developing in terms of quality, capacity and productivity [6]; [7].

In most of the other developing and developed countries the governments set up a target to achieve a specified productivity growth rate to increase the productivity level in different industries including building and other construction industries [8]. However, due to lack of studies and lack of data and information available in Sri Lanka, the government or the authorities involved in any sector (Buildings, Roads, Water, etc.) in the construction industry do not know the present situation of the productivity level and its trend.

Productivity is a major determinant of a countryís competitive advantage and distribution of incomes [13], and then the incorrect measurement and misinterpretation of the causes of productivity growth are important policy issues [12].

Although the current official measures of construction productivity tend to rely on labour

\footnotetext{
Eng. Dimuth Navaratna, C.Eng. MIE(SL). B.Sc. Eng. (Perndenija). M.Sc. Construction Project Management (Moratuwa), Mannger. Haycarb Group and Overall in-charge of Siructural Designs and Construrtion Division of Puriter Limited.

Eng. (Professor) A $\boldsymbol{X} W$ Jayawardane, C.Eng., FIE(SL), BSe Eng (Moratuwa), MSc. Construction (Loughborrough). PhD (Loughbonough). Professor of Civil Engineering and currently the Denn of the Faculiy of Engineering, Universily of Moratuw'a.
} 
productivity (mainly owing to data inadequacies), it is increasingly realized that such partial measures are potentially misleading because the change in output is often caused by changes in all inputs rather than a single input. However, from the early 1980s, the major statistical agencies in the world began to publish TFP indices at both the industry and national levels [10]; [12].

There have been several attempts to measure site level and enterprise level productivity in Sri Lanka construction industry [6]; [7]. However there had been no significant attempt to measure the TFPG in the construction industry at macro level, perhaps due to the complexities of such studies and lack of data and information available in Sri Lanka. Thus a research study was carried out (a) to study various techniques and tools available to measure productivity in an industry at macro level (b) to assess the annual TFPG levels and its trend in the building construction industry of Sri Lanka, (c) to identify the causes of productivity variations in the building construction sector, and (d) and assess Sri Lankaís readiness in accurately measuring the TFPG. This paper presents key findings of this study.

\section{Literature Review on Productivity Measurement Tools and Techniques}

In general, productivity means the efficiency of a production activity. Productivity could be measured from the ratio of output to input. Therefore, Single Factor Productivity (SFP) is defined as the ratio of output to amount of single input factor [4]. For example, Labour productivity, Capital productivity, Energy productivity, etc. Multi Factor Productivity is defined as the ratio of output to aggregate of several inputs with regard to the production activity. Total Factor Productivity is measured considering all inputs with respect to a production activity. Broadly defined, TFP growth includes all qualitative changes in labour and capital, including changes in their composition as well as demand intensity, economic restructuring and technical progress [11].

TFPG is a measure of how efficiently that the available resources are used in an economy. In a production process, many factors of production inputs may be used. Hence changes in the quality and quantity of inputs affect the productivity measure in terms of a single input. For example, in a production process, both labour and machinery are used together. If the number of employees is kept unchanged and the use of machinery is increased, there would be an increase in per capita output. This will show an increase in labour productivity, even though there is no improvement in quality of labour or technological skill of labour. SFP will represent only a partial picture of technology change and therefore TFP growth measurement is very important to understand the full picture of a production process. The basic concept behind TFP is to obtain the ratio of output to some kind of aggregate index that combines the quantity of all factors of production inputs used in the process. Therefore, TFP captures the effects of qualitative improvements that allow output to increase without any use of additional inputs. TFP measures the productivity of a composite of all factor inputs (total factors) of production.

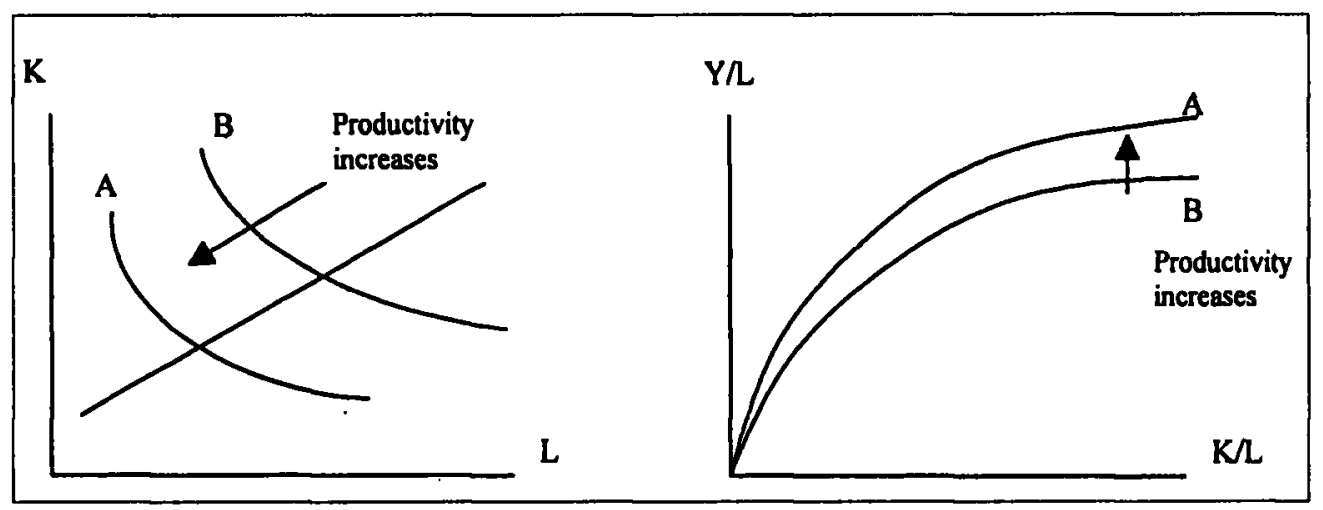

Figure 1 - Productivity Change due to a Shift of a Production Function

(Source: Wahab Mahainud, APO 2004) 
Productivity measurement tools and techniques are mainly divided in to two categories.

1. Productivity measurement at site or factory level (Micro level)

2. Productivity measurement in industrial or national level (Macro Level) ñ Estimating Total Factor Productivity Growth (TFPG)

The focus of this research is the productivity measurement at macro level.

TFP growth is related to a shift of a production function.

Figure 1 represents different behaviours of Capital input (K), Labour input (L) and Output $(Y)$ of a production function. The curves $A$ and $B$ represent the same amount of output. When the technology improves, curves shift from B to A thus improving productivity.

There are several important factors for the TFP growth of an economy or of an industry as follows.

1. Quality changes of inputs

- Labour (examples: Education, training, health, age, sex, types of work, work attitude, etc.)

- Capital (examples: Composition of fixed assets, equipment, quality of maintenance, kaizen, etc.)

2. Better management

- Reallocation of personnel, Change in management system, Restructuring, Change in marketing and Change in procurement

3. Better work environment with new technology

4. Better economic and social environment

- Deregulation, Law and order, Security, Social and political stability

5. Better and innovative production systems

6. Outside conditions

- Business fluctuation (capacity utilization), Natural conditions such as weather, Accidents, etc.

In general, TFP measurement approaches are divided in to two as shown below.

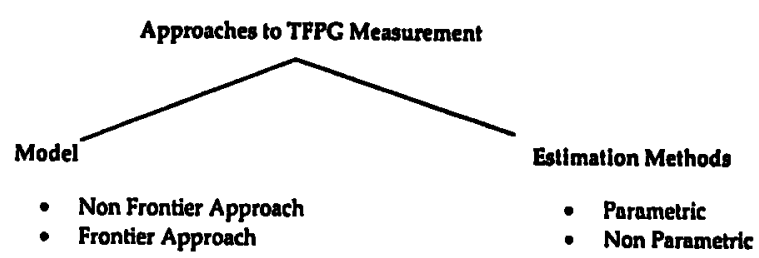

Modeling (Frontier approach - productivity and efficiency are separated and TFP is the slift of the production function and change in efficiency. Non frontier approach - Observed points give the production function and all observed points are at the efficient points. Output growuth that is not explnined by the incrense of inputs is estimnted ns TFP).

Estimation methods (Parametric - Econometric estimation is based on estimating a production function and then the marginal productivities. Non Parametric estimation using growth accounting and indexing). In general, TFP growth measurement at macro level is mainly carried out using one of the non parametric estimation methods (Index Number theories \& methods and Growth Accounting), which are very common and popular [4]. However, there are several other methods available such as the Empirical Research methods, different methods of computer modeling (example: Artificial Neural Network Modeling, ANN), etc., which fall into the above two main categories to estimate TFP at macro scale.

Most of the previous research works were carried out based on the Index Number Theories and using. Growth Accounting Method. Therefore, the literature review was limited to those areas.

\section{Research Methodology}

Transcendental Logarithmic (translog) production function, which is commonly called Tornqvist index is one of the most common methods of finding the TFP growth at macro level. There have been number of studies carried out in countries such as Singapore, Japan, Thailand, Malaysia, and India using this technique [1]. The researchers who have used this method have emphasized that the technique is very reliable, user friendly and straightforward to find TFP growth in an industry or national level. Therefore, this technique was chosen in the first instance to evaluate the level of TFPG in the Sri Lanka construction industry. 
Following derivation of the Tornqvist formula to find out TFPG in the building construction industry ñ Sri Lanka is similar to the derivation of the Tornqvist index formula described in the [14], finding Multifactor Productivity Growth in an industry or a national economy.

$$
\operatorname{TFP}_{1}=\frac{Y(t)}{I(t)}
$$

Where TFP at period of time $t$ is TFP, which is defined by the ratio of output in period $t(Y(t))$ and a combined input index $(I(t))$. The index $I(t)$ is computed as a Tornqvist Index, and is calculated recursively from the geometric measure and the growth rates of the labour input $(\mathrm{L}(\mathrm{t}))$ and the capital input $(\mathrm{K}(\mathrm{t}))$. For two time periods $t$ and $t-1$,

$$
\frac{l(t)}{I(t-1)}=\left(\frac{K(t)}{K(t-1)}\right)^{\bar{\sigma}_{1}}\left(\frac{L(t)}{L(t-1)}\right)^{\sigma_{L}}
$$

Combining the above two equations and taking the natural logarithmic form for the both sides of the equation,

$$
\operatorname{Ln} \frac{Y(t)}{Y(t-1)}=\bar{\theta}_{K} \operatorname{Ln}\left(\frac{K(t)}{K(t-1)}\right)+\bar{\theta}_{L}\left(\frac{L(t)}{L(t-1)}\right)+T F P_{t-1, t}
$$

Where

- $\bar{\theta}_{i}=\frac{1}{2}\left[\theta_{i}(t)+\theta_{i}(t-1)\right]$ for $\mathrm{i}=\mathrm{K}, \mathrm{L}$

- $Y, L$ and $K$ denote output, input of labour, and input of capital services respectively.

- $\bar{\theta}_{k}$ and $\bar{\theta}_{L}$ represent the respective shares of capital and labour input in total factor payments averaged over time periods $t$ and t-1.

- $\mathrm{TFP}_{\mathrm{t}-1, \mathrm{t}}$ is the translog index of TFP growth. This indicates the residual that registers those changes in output which are not due to changes in labour and capital inputs.

The above formula shows the average rate of TFPG between two discrete points in time $t$ and $t-1$ and that is expressed as the difference between successive logarithms of output minus the weighted average of the differences between the successive logarithms of capital and labour inputs which are given by the average value shares.
The following measurement data will be used to find TFP growth in the building construction industry - Sri Lanka.

a) Measure/Estimate of Output: Due to lack of data available in Sri Lanka, the selected output measure is somewhat different from that used in key research articles. In this case, output is estimated in physical units (building floor area constructed annually) similar to Melborne [9].

b) Measure of Labour Input: In this case, information available in the construction survey report published by DC\&S was readily available. Therefore labour input cost was simply extracted from the published reports on Annual Survey of Construction Industries [2]. No reliable data is available at the DC\&S to distinguish these costs by categories such as experience, age, gender and quality differences.

c) Measure of Capital Input: The Capital input was considered as all other input costs such as equipment, machinery, land, services, etc. except labour and construction material cost that could be extracted from the published reports on Annual Survey of Construction Industries [2].

d) Estimate of factor share inputs for Capital and Labour: Due to non availability of reliable published data on the relationship between the Capital and labour contributions of the building construction sector and the GDP growth in Sri Lanka, the labour share was calculated as a ratio of the total paid salary of the labour employed in the sector to the total value of work done excluding material cost. The capital factor share was simply calculated by subtracting the labour share by one, assuming the constant returns to scale.

\section{Total Factor Productivity Growth}

According to the results obtained from the above computation, there is no specific trend of TFPG in Sri Lanka building construction industry during 1995-2001. TFPG in the building sector shows high fluctuation during this study period. The results of the study indicate that TFPG has a positive trend until 1997 and there is a drastic drop in 1998 to a negative growth rate and a further drop in 1999 to record the 
Table 1 - Summary of TFPG in the Sri Lanka Building Construction Industry

\begin{tabular}{|c|c|c|c|c|}
\hline \multirow{2}{*}{ Year } & OUTPUT (Y) & \multicolumn{2}{|c|}{ INPUTS } & RESULT \\
\cline { 2 - 5 } & $\begin{array}{c}\text { Floor Area } \\
\text { Constructed } \\
\text { (Y)/ft2 }\end{array}$ & $\begin{array}{c}\text { Labour Contribution } \\
\text { for building Cost } \\
\text { (L)/Rs. }\end{array}$ & $\begin{array}{c}\text { Capital Contribution } \\
\text { for building Cost } \\
\text { (K)/Rs. }\end{array}$ & TFPG \\
\hline 1995 & $2,073,688.88$ & $377,142,685.40$ & $893,428,568.92$ & - \\
1996 & $764,499.41$ & $215,008,133.39$ & $146,398,711.90$ & 0.069 \\
1997 & $3,682,122.49$ & $568,571,503.36$ & $126,641,663.85$ & 0.803 \\
1998 & $6,824,387.03$ & $1,943,382,756.65$ & $451,405,398.87$ & -0.620 \\
1999 & $3,383,299.76$ & $974,876,059.76$ & $908,296,486.68$ & -0.682 \\
2000 & $4,441,420.65$ & $1,392,655,310.00$ & $842,747,143.00$ & 0.078 \\
2001 & $2,634,178.21$ & $715,163,564.82$ & $815,261,398.40$ & -0.193 \\
2002 & & & & \\
\hline
\end{tabular}

minimum TFPG rate in the building construction sector during the study period. Since year 2000 TFPG has been revolving around zero. TFPG is a measure of comparison factor of two time periods. Therefore TFPG rates in 1995 and 2002 are not zero but cannot be established due to non availability of data before 1994and beyond 2001. Table 1 and Figure 2 show the TFPG during the study period.

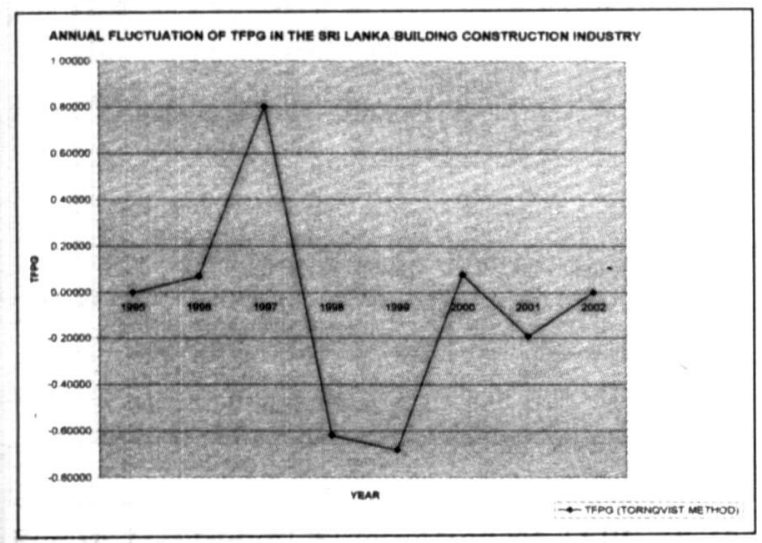

Figure 2 - Annual Fluctuation of TFPG in the Sri Lanka Building Construction Industry

\section{Analysis}

One of the main reasons for this fluctuation is the effect of capacity utilization rate due to stability and strength of the economy. The building construction sector in Sri Lanka is very sensitive and generally fluctuates with the investment of the government, private sector and of its general public. The main reason for the positive trend in TFPG from 1995 to 1997 was due to the healthy investment pattern of the country during that period. In 1998 there was increased investment for building construction. However there was a very high labour input (approximately 4 times compared to 1997) and high capital input (approximately 3.5 times compared to 1997) for the output (construction of $6,824,387 \mathrm{sqft}$ of building floor area, which is about two times the previous year 1997) in 1998. This explains the point that even there is a higher output produced with very high contribution of inputs, it may result in a lower TFPG in an industry or an economy. In 1999, to produce a similar output as 1997, almost double the quantity of labour and seven times of capital services was deployed thus resulting a very low TFPG. Since the entire study was based on the DC\&S database, the reliability of the results depends on the reliability of data. These results of TFPG do not give a strong confidence on the reliability and completeness of data, which was used for the estimation of TFPG in the building construction sector in Sri Lanka.

The increase in population and high unemployment (low permanent employment) has recorded a high casual labour force in the construction sector. When the construction projects are prolonged due to lack of funds and due to other reasons, this type of imbalances in inputs and outputs would arise and would lead to lower productivity.

\section{Discussion}

By learning the background and applicability of theories and methodologies, which are designed to estimate TFPG at national and industrial scale, it was found that a suitable and a complete database is essential to have in any country to obtain reliable results.

In other countries such as Singapore, Japan, Korea, etc., data is collected from the industry 
by a single organization and updated data are published quarterly (in some occasions monthly) via interim reports, magazines, and through the Internet. The reliability of these data is much better according to the researchers, who have carried out similar research studies in the past. Therefore, it is important to identify the root causes for not having reliable data in the construction sector in Sri Lanka.

Presently, the task of collecting construction data is assigned to DC\&S (initiated on the request by ICTAD) which carries out a survey annually using a questionnaire from a sample of government and private construction contractors. However, the response rate from the contractors is very low.

It was also found that the follow up from the construction related organizations such as ICTAD, NCCASL (National Construction Contractors Association in Sri Lanka), etc., is inadequate with regard to improving this data collection mechanism and providing feedback to DC\&S. Hence the feedback from the contractoris information is not specific and the information regarding the construction output is hardly available. Therefore, description of the work carried out and the work volume is not identifiable from the information received. For example, the composition of the type of buildings that are constructed is not specified in the DC\&S construction data survey. The involvement of labour and capital input composition depends on the type, size and time of completion of the building project and this gives different rates of TFPG. Any physical attribute (building floor area, no. of building units, etc.) could be taken as the output. Generally, TFPG fluctuation does not change with the output measure. However, the results could be different due to accuracy, effectiveness and completeness of data.

According to the information extracted from the data collection organizations in other countries such as in Singapore, the contractoris questionnaire is designed to obtain information on project basis. For example, if a contractor has carried out a multi storied building, then the information is gathered on the nature of that construction, labour involvement, tools, equipment and machinery used, different materials, breakdown of expenses, total output in terms of floor area, etc.
Most of the registered contractors in ICTAD and other local authorities and private / unregistered contractors refuse to disclose accurate information due to various reasons some of which are indicated below. However, these reasons are not addressed effectively.

1. Confidentiality of technical information Some contractors do not want to send the design, financial and labour statistics and data to an outside party.

2. Evasion of government laws and regulations ñ Some contractors feel that divulging income and labour information will lead to government laws being imposed on them resulting in tax payments.

3. Lack of interest and the attitude - Some contractors do not bother about sending this information to an outside party spending their time. They think that they do not obtain any benefit by sending this information. Some contractors send incomplete and false data to get rid of the responsibility.

4. Non availability of competent staff - Most of the contractors do not have/want to allocate a person who has the capability to formulate and answer the questions asked in a more sensible manner.

5. Non availability of data with the contractors - Most of the medium to small contractors are not sufficiently organised and do not keep records, accounts, data and historical documents to extract the data required to fill such questionnaires.

6. Difficulties in understanding the questionnaire sent by DC\&S $\tilde{n}$ The complexities in the present format of the questionnaire leads to difficulties in comprehension to the contractors.

This deficiency in data is common not only in the construction sector but also in most of the other industrial sectors in Sri Lanka. There is a significant contribution from the private contracts and the foreign funded mega scale projects which are carried out with the help of the local resources (labour and capital). Unlike in the other countries there is no single place available to extract the information on these mega projects carried out in Sri Lanka. 
It was also highlighted that the present technically skilled staff in the DC\&S of Sri Lanka is insufficient for compiling, sorting and adjusting raw data received from the contractors. The assumptions and adjustments made during this data processing could have a direct impact on the final outcome of results.

The study revealed that Sri Lanka has several mechanisms to obtain industry statistics from sources such as Central Bank, Department of Census and Statistics and Institute for Construction Training and Development. However, the data and information available at these institutions are not complete to identify actual industry performance with regard to quality and productivity. Therefore this study clearly identified the need for greater commitment by the construction industry policy makers to put in place mechanisms to collect reliable industry statistics to assess the industry performance with regard to quality and productivity.

ICTAD being the Construction Industry Authority responsible for the development of the construction industry should take the leadership to establish this type of a strong database. However collection, compilation and publishing such data may be carried out by the DC\&S. It is important to have one centralized, reliable and complete construction data base within DC\&S, rather than having several incomplete databases, which are not compatible to each other. When there is one data collection organization, there is a higher control over confidentiality of such data and therefore the contractors will have more confidence to disclose their information. It is also recommended that Central Bank of Sri Lanka to obtain information from DC\&S in future for their annual report, etc., once this centralized data collection system is implemented.

\section{Conclusions}

This study revealed that there are many popular methods available to estimate TFPG in an industry or an economy. These include Index Number Theories, Growth Accounting Method together with Tornqvist Index Method.

This research used the Tornqvist Index Method, which is generally called as Transcendental Logarithmic formula to estimate the TFPG in the
Sri Lanka Building Construction Industry for the study period 1995-2001. Out of the available methodologies, the Tornqvist Index method is the most suitable and the simplest method to estimate TFPG in the building construction sector, when the required data availability is limited, incomprehensive and incomplete which is the case in Sri Lanka.

The TFPG in the building construction industry in Sri Lanka remains almost zero in the recent past but with very high fluctuation in many years. In ideal situations, TFPG in an industry or in a national economy should give a particular trend to explain clearly the reasons for that trend. However in reality, obtaining TFPG results with a particular trend would be a difficult task due to the reasons such as not having a very accurate database showing the actual situation of the sector, and also since the sector does not behave according to the assumptions that have been stated to use the above methodology and the capacity utilization rate.

This study gives all relevant stakeholders a new vision on the productivity enhancement in the construction sector in general (specially in the building construction sector), methodologies of assessing TFPG, importance of the TFPG and its determinants, and importance to have a better data set to more accurately estimate TFPG in the future while appreciating the effort and the commitment taken by the Department of Census and Statistics of Sri Lanka albeit some deficiencies in the process.

\section{Recommendations}

1. Tornqvist Method is the most suitable method to estimate TFPG in the building construction sector in Sri Lanka considering its validity, simplicity and limitations of available data.

2. The output figure required for the Tornqvist Method can be considered as the component of GDP for the construction sector. If the study is limited to a specific section such as Building Sector, a physical output is required.

3. Two inputs (Labour (L) and Capital (K)) should be required to estimate TFPG using Tornquist Formula. Labour input is 
measured in labour hours spent or total salary paid. This construction labour data should have the compositional and quality changes such as gender, educational levels, age, experience, skills, etc. Ideally, the capital input should be the capital services per unit time. Since this type of information is seldom in most of the countries, it is recommended to have at least the data on the capital services such as the data on fixed assets.

4. Commercial Price Index for shops and offices and Domestic price Index for Machinery and Transport Equipment are required for data adjustment. Therefore it is important for DC\&S to publish this information related to building and overall construction sector quarterly or annually.

5. While appreciating the effort taken by the DC\&S, it is recommended to continue the data collection, data analyzing and publishing valuable \& reliable construction information with identified improvements to overcome the deficiencies discussed earlier.

7. To improve the poor response rate of feedback, it is recommended that DC\&S and ICTAD to have more follow up strategies including the following.

- To have a confidentiality agreement between the contractor and DC\&S, and buildup a strong understanding between the two parties.

- ICTAD to have effective awareness sessions on importance of such reliable and strong centralized database related to the construction industry and its usefulness for the contractors, construction industry and to the whole country. This will improve the contractorsi attitudes on this data collection survey.

- ICTAD to impose strict rules in contractor registration to submit true and reliable data, to form a computerized data base and support DC\&S to formulate their comprehensive database. It is important not to collect duplicate data and information by DC\&S and ICTAD.

- Bring the laws related to this data collection into effect and penalize those who do not send their business information.

- ICTAD should follow up to check regularly whether the registered contractors are maintaining actual records and information related to their construction activities. ICTAD could conduct seminars and training sessions on this and encourage them to store data in computers.

\section{References}

1. Asian Productivity Organization (2004) Total Factor Productivity growth, a Survey Report.

2. Department of Census and Statistics of Sri Lanka (1994 ñ 2001) Annual Construction Survey Reports.

3. Department of Census and Statistics of Sri Lanka (1995 - 2001), National Accounts of Sri Lanka.

4. Diewert, W. E. and Nakamura, O. A. (2002) Index Number Concepts, Measures and Decompositions of Productivity growth.

5. ICTAD, Standard Bidding Document, Clause 30.0

6. JAYAWARDANE, A. K. W. and Pandita, H. G. W. (2003) Understanding and mitigating the factors affecting construction delays, Engineer, Journal of the IESL, Vol. XXXVI No. 2.

7. JAYAWARDANE, A.K.W. (1995) Material and Labour Wastage on Sri Lankan Construction Sites, Asia Pacific Building \& Construction Management Journal, 1(1), Hong Kong.

8. Mao Zhi, Goh Bee Hua, Wang Shouquing and George Ofori (2002) Forecasting Construction Industry-level Total Factor Productivity Growth using Neural Network Modeling, University Of Singapore.

9. Melbourne WSAA. (1993) Measurement of Total Factor Productivity in Major Water Utilities: Melbourne Case Study, Report No. WSAA 65 (1993).

10. US Bureau of Labour Statistics (1983) OECD 1996.

11. Wahab Muhamad. (2004) Total Factor Productivity and Industrial Development, seminar of Total Factor Productivity (TFP) ñ Malaysia by Asian Productivity Organization

12. Willie Tan. (2000) Total Factor Productivity in Singapore Construction, Construction and Architectural Management, Vol7(2), pp154-158

13. World Bank (1984) Porter. (1985) The construction Industry. World Bank, Washington DC.

14. http;//www.pc.gov.au, ABS Cat. No. 5233.0, visited 04th April 2005 